\title{
Características Mecânicas de Materiais para Pavimentos: Estudo de Caso Laboratório x Campo
}

\author{
Mechanical Characteristics of Materials for Pavement: a Case Study Laboratory and Field
}

\author{
G. M. Costa ${ }^{1 *} ;$ A. T. de Mendonça ${ }^{2} ;$ F. S. Albuquerque ${ }^{1} ;$ T. M. A. Albuquerque ${ }^{2}$ \\ ${ }^{1}$ Departamento de Engenharia Civil, Universidade Federal de Sergipe, 49100-000, São Cristóvão - Sergipe, Brasil \\ ${ }^{2}$ Departamento de Engenharia Civil, Instituto Federal de Sergipe, 49055-260, Aracaju-Sergipe, Brasil
}

*gessyca.menezes@hotmail.com

(Recebido em 12 de junho de 2015; aceito em 08 de novembro de 2015)

\begin{abstract}
O setor rodoviário representa o maior meio de transporte utilizado no Brasil, tanto para pessoas como para cargas. As modificações, nas últimas décadas, de cargas máximas e materiais utilizados em pavimentos rodoviários, torna necessário um estudo mecânico dessas estruturas para garantir sua durabilidade. A determinação do módulo de resiliência destes materiais (necessários nos estudos mecânicos) pode ser realizada por meio de ensaios laboratoriais ou por retroanálise de bacias deflectométricas obtidas em ensaios não destrutivos de campo. Assim, diversos programas computacionais podem ser utilizados para calcular as tensões, deformações e deslocamentos que ocorrem na estrutura com a aplicação de cargas. São exemplos destes programas o EVERSTRESS 5.0 e o EFin3D, baseados nos Métodos das Camadas Finitas e dos Elementos Finitos, respectivamente. Neste trabalho, realizou-se um estudo comparativo de módulos de resiliência das camadas do pavimento obtidos em laboratório e em campo, estabelecendo também suas implicações quando utilizados nos cálculos de tensões e deformações para fins de projeto. Este estudo foi realizado para uma seção de pavimento existente na BR-101/SE, construída com revestimento com ligante modificado por SBS e base de BGTC, para o qual foi avaliado o efeito destas diferenças em termo de tensões, deformações e deslocamentos calculados para cada situação. Pôde-se observar diferenças importantes nos resultados das análises, devido às diferenças nos módulos de resiliência obtidos em campo e laboratório (principalmente para o revestimento, sub-base e subleito). A configuração estrutural obtida por ensaios de laboratório acabou subestimando pela metade o real desempenho estrutural do pavimento observado em campo. Ainda, as tensões verticais calculadas pelo método de camadas finitas superaram as de elementos finitos.

Palavras-chave: tensões e deformações, avaliação estrutural, trecho monitorado.
\end{abstract}

The road sector represents the largest means of transport used in Brazil, for both people and cargo. The changes in recent decades, of maximum loads and materials used in road pavements, make necessary a mechanical study of these structures to ensure its durability. The determination of the resilience modulus of these materials (required in mechanical studies) can be accomplished through laboratory tests or by retroanalise of deflectometric basins obtained in nondestructive testing of field. Thus, various computer programs can be used to calculate the stresses, deformations and displacements that occur in the structure with the application of loads. Examples of these programs are the EVERSTRESS 5.0 and EFin3D, based on Methods of Finite Layers and Methods of Finite Elements, respectively. In this work, was done a comparative study of pavement layers of resilience modules obtained in the laboratory and in the field, also establishing its implications when used in the calculations of stresses and strains for design purposes. This study was conducted to a section of existing pavement on BR-101, Northeast Brazil, built with Binder coating modified by SBS and cement-treated crushed rock base, for which it was evaluated the effect of these differences in terms of stresses, deformations and displacements calculated for each situation. It was observed significant differences in the analyses results, due to differences in resilience modules obtained in the field and laboratory (mainly for surfacing and subgrade). The structural configuration obtained by laboratory tests underestimating just half the actual structural performance of the pavement observed in the field. Further, the vertical stress calculated by the Method of Finite Layers exceeded the Method of Finite Elements.

Keywords: stresses and deformation, structural assessment, monitored 


\section{INTRODUÇÃO}

O pavimento é uma estrutura de camadas finitas que tem como objetivo permitir o tráfego de veículos com segurança e conforto ao rolamento, interligando dois ou mais pontos [1]. As características elásticas e a composição de cada camada influenciam diretamente no comportamento da estrutura do pavimento.

A determinação dessas características pode ser feita por dois métodos: ensaios laboratoriais e em campo. Contudo, as condições de campo não são adequadamente reproduzidas em laboratório, e, por isso, podem gerar diferenças na avaliação estrutural e no dimensionamento de pavimentos. Para mensurar o grau dessas diferenças, este trabalho propõe uma comparação entre os resultados da análise mecanística do pavimento de um trecho monitorado da BR101/SE. Foram utilizados os resultados de módulo de resiliência obtidos com dados de ensaios de carga repetida (em laboratório) e dados retroanalisados de bacias deflectométricas (obtidas com equipamento Falling Weigh Deflectometer - FWD). Além disso, foi avaliada a diferença de vida de serviço para esta estrutura de pavimento a partir da análise tensão e deformação utilizando características elásticas obtidas pelos dois métodos.

Também foi possível realizar uma comparação entre os métodos cálculo Camadas Finitas e Elementos finitos, através dos softwares EVERSTRESS 5.0 e EFin3D.

\section{ENSAIO DE MÓDULO DE RESILIÊNCIA}

O termo resiliência é definido como a energia armazenada num corpo deformado elasticamente, a qual é devolvida quando cessam as tensões causadoras de deformação [2].

O ensaio do módulo de resiliência em misturas asfálticas é realizado aplicando-se uma carga repetidamente no plano diametral vertical de um corpo de prova cilíndrico regular. Essa carga gera uma tensão de tração, transversalmente ao plano de aplicação da carga. Mede-se então o deslocamento diametral recuperável na direção horizontal correspondente à tensão gerada (Figura 1), numa dada temperatura (T). Os corpos de prova cilíndricos são de aproximadamente $100 \mathrm{~mm}$ de diâmetro e 63,5 mm de altura, caso sejam moldados no compactador Marshall, ou de $100 \mathrm{~mm}$ de diâmetro e altura entre $35 \mathrm{~mm}$ e $65 \mathrm{~mm}$, caso tenham sido extraídos de pistas ou de amostras de maiores dimensões [1].

Segundo o DNIT (2006) [3], os corpos de prova para solos são obtidos por compactação por impacto, com dimensões de $100 \mathrm{~mm}$ de diâmetro e $200 \mathrm{~mm}$ de altura. A instalação destes na câmara triaxial (Figura 1) exige o máximo de cuidado, pois, dela depende a qualidade do ensaio. Recomenda-se que o corpo de prova seja assentado em pedra porosa e que uma membrana, sem furos, o envolva. Por fim, é feita a instalação dos transdutores (LVDT) para medição das deformações verticais.

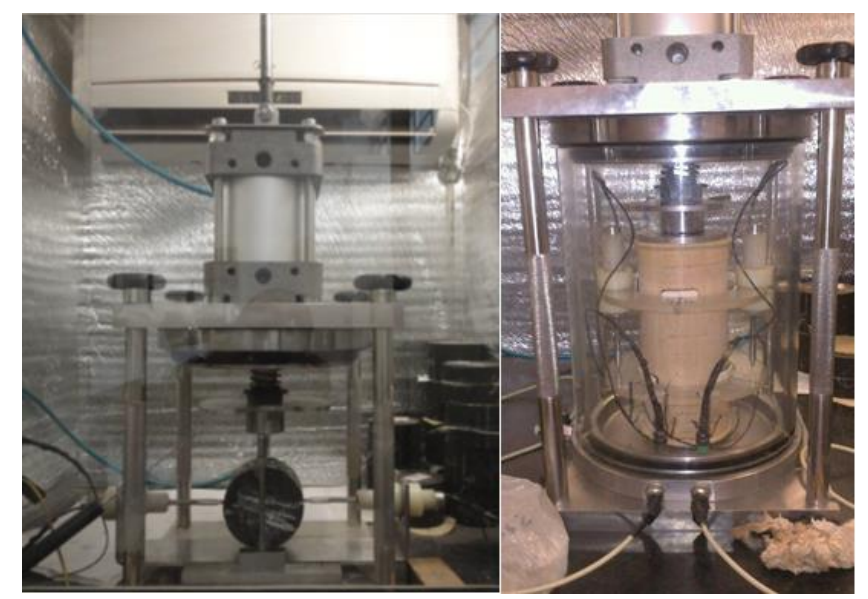

(a)

(b)

Figura 1: Ensaio de módulo de resiliência: (a) em misturas asfálticas; (b) em solos (Equipamento SIEMBS - Geopav - imagem obtida em 2013). 
A amostra passa por um condicionamento prévio para reduzir a influência das deformações plásticas [4]. Em seguida, o ensaio é realizado e consiste na aplicação de carga em $0,1 \mathrm{~s}$ e repouso de $0,9 \mathrm{~s}$, com o objetivo de simular o tráfego de veículos. De acordo com a Norma do DNIT ME 134/2010 [5], são aplicados 200 repetições em 3 pares de tensão confinante e tensão desvio.

Para materiais que não apresentam módulo de resiliência constante ou linear em sua fase elástica, é necessária a definição de modelos constitutivos que possam prever as variações de módulo de resiliência em função dos níveis de tensão que ocorrem nas estruturas do pavimento. Isto acontece quando se empregam teorias não-lineares para o cálculo de deformações e tensões nas camadas. O modelo proposto por Hicks (1970) [6], expresso pela equação 1, determina o comportamento tensão versus deformação de solos granulares e é muito usado devido a sua simplicidade na obtenção das constantes.

$$
M r=k_{1} \sigma_{3}^{k_{2}}
$$

A partir da equação 1 , conclui-se que quanto maior for a tensão de confinamento $\left(\sigma_{3}\right) \mathrm{em}$ ação, maior será o módulo de resiliência do material (MR).

Hicks (1970) [6] também propôs um modelo para solos finos, em função da tensão desvio e expresso pelas equações 2 e 3 .

$$
\begin{aligned}
& M R=k_{2}+k_{3}\left(k_{1}-\sigma_{d}\right), \text { para } \sigma_{d}<k_{1} \\
& M R=k_{2}+k_{4}\left(\sigma_{d}-k_{1}\right), \text { para } \sigma_{d}>k_{1}
\end{aligned}
$$

Em que $\mathrm{k}_{1}, \mathrm{k}_{2}, \mathrm{k}_{3}$ e $\mathrm{k}_{4}$ são parâmetros de resiliência determinados em ensaios triaxiais de carregamento repetido sob tensões-desvios $\left(\sigma_{d}\right)$.

\section{ENSAIO COM FALLING WEIGHT DEFLECTOMETER}

O Falling Weigth Deflectometer (FWD) é um equipamento que mede os deslocamentos elásticos de um pavimento pelo impacto causado pela queda de um peso suspenso a certa altura (Figura 2), sobre amortecedores que comunicam o choque a uma placa metálica apoiada sobre o pavimento no ponto de leitura de deflexão máxima [1]. A placa metálica tem $30 \mathrm{~cm}$ de diâmetro e a carga transmitida através dela é medida através de uma célula de carga. Sua aplicação tem duração de 25 a $30 \mathrm{~ms}$, que corresponde à passagem de um veículo com velocidade de 60 a 80 $\mathrm{km} / \mathrm{h}[7]$.

O ensaio consiste em se aplicar a carga de impacto e ler os deslocamentos em vários sensores colocados ao longo de um suporte em posições convenientemente escolhidas para se obter a linha de deslocamentos. Essa linha é denominada bacia deflectométrica do pavimento e é utilizada para estimar os módulos de elasticidade das camadas por retroanálise, o que permite uma avaliação estrutural mais adequada do pavimento pelo princípio da mecânica dos pavimentos [1].

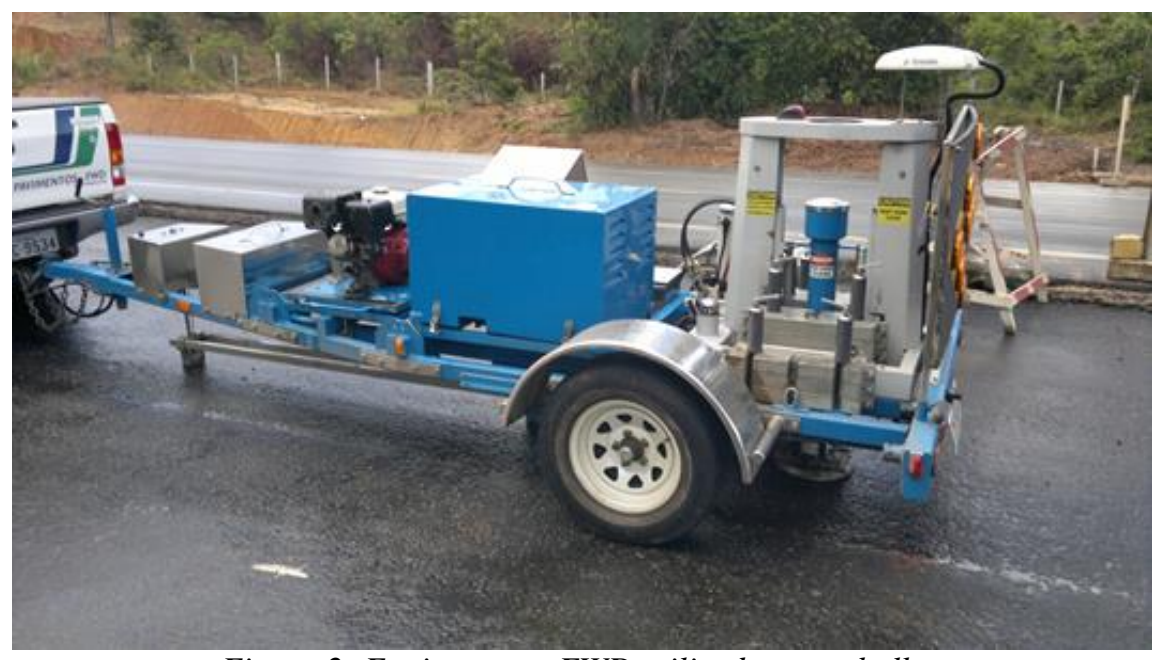

Figura 2: Equipamento FWD utilizado no trabalho. 


\section{TEORIA DO SISTEMA DE CAMADAS FINITAS E DOS ELEMENTOS FINITOS}

Os métodos mais comuns para análise de tensões, deformações e deslocamento em pavimentos são a teoria do sistema de camadas elásticas e dos elementos finitos.

A Teoria do Sistema de Camadas Elásticas (TSCE) permite a determinação de estado de tensões e deformações em vários pontos das camadas, utilizando o coeficiente de Poisson e o módulo de resiliência dos materiais, a espessura das camadas e a magnitude e distribuição das cargas como dados de entrada [2].

A TSCE tem as seguintes condições [8]:

- Todas as camadas são elásticas e lineares em termos de respostas dos materiais;

- Todas as camadas são infinitas na direção horizontal;

- Todas as camadas possuem espessuras constantes;

- Não existem descontinuidades a menos na superfície do pavimento;

- Não existem forças de gravidade agindo no sistema;

- Não existem nem deformações nem tensões iniciais residuais.

A TSCE de Burmiter assume uma função biarmônica para a determinação das respostas (tensões, deformações e deflexões) em camadas e pontos de interesse. Essas respostas satisfazem as equações de equilíbrio, a compatibilidade entre deslocamentos e deformações e a lei de Hooke generalizada em coordenadas cilíndricas [8].

O Método dos Elementos Finitos (EF), por outro lado, transforma um problema específico em várias regiões de geometria simples, tais como triângulos, quadriláteros, tetraedros e hexaedros, utilizando as equações diferenciais. Essas regiões formam um conjunto de pontos (conhecidos como nós) e o conjunto de elementos é denominado como malha de elementos finitos [9].

Em cada elemento ocorre o cálculo das forças internas, levando em consideração as propriedades geométricas e do material. Para determinar tais esforços uma sequência de etapas é obedecida. Monta-se a matriz de rigidez da estrutura através da matriz de rigidez de cada elemento. Determina-se o deslocamento nodal da estrutura inteira, e, também, os de cada elemento, encontrando-se assim as forças internas quando usando as condições de contorno como as restrições e o carregamento atuante [10].

\section{CARACTERIZAÇÃO DO TRECHO MONITORADO}

O trecho monitorado é constituído por pavimento asfáltico da obra de duplicação da BR101/SE, localizado entre os $\mathrm{km} \mathrm{93,4} \mathrm{e} \mathrm{123,0.} \mathrm{O} \mathrm{tráfego} \mathrm{é} \mathrm{classificado} \mathrm{como} \mathrm{intenso} \mathrm{com} \mathrm{a}$ presença considerável de veículos comerciais. A projeção de tráfego foi obtida a partir de contagem em campo e o número $\mathrm{N}$ (número de repetições do eixo padrão de 8,2tf) foi determinado neste trabalho pelo método da AASTHO (1993) [11], com ano inicial igual a 2012 e final 2021 (Figura 3). Na Tabela 1 é apresentada a seção transversal do trecho monitorado.

Tabela 1: Detalhamento da seção transversal do trecho monitorado.

\begin{tabular}{ccc}
\hline Camada & Espessura & Material Empregado \\
\hline Capa & $5,0 \mathrm{~cm}$ & CBUQ com polímero SBS, faixa C \\
\hline Binder & $7,5 \mathrm{~cm}$ & CBUQ faixa B \\
\hline Base & $15 \mathrm{~cm}$ & Brita Graduada Tratada com Cimento - BGTC - 3\% \\
\hline Sub-base & $15 \mathrm{~cm}$ & Solo granular - CBR $\geq 20 \%$ \\
\hline Subleito & - & Solo argiloso - CBR $\geq 7 \%$ \\
\hline
\end{tabular}




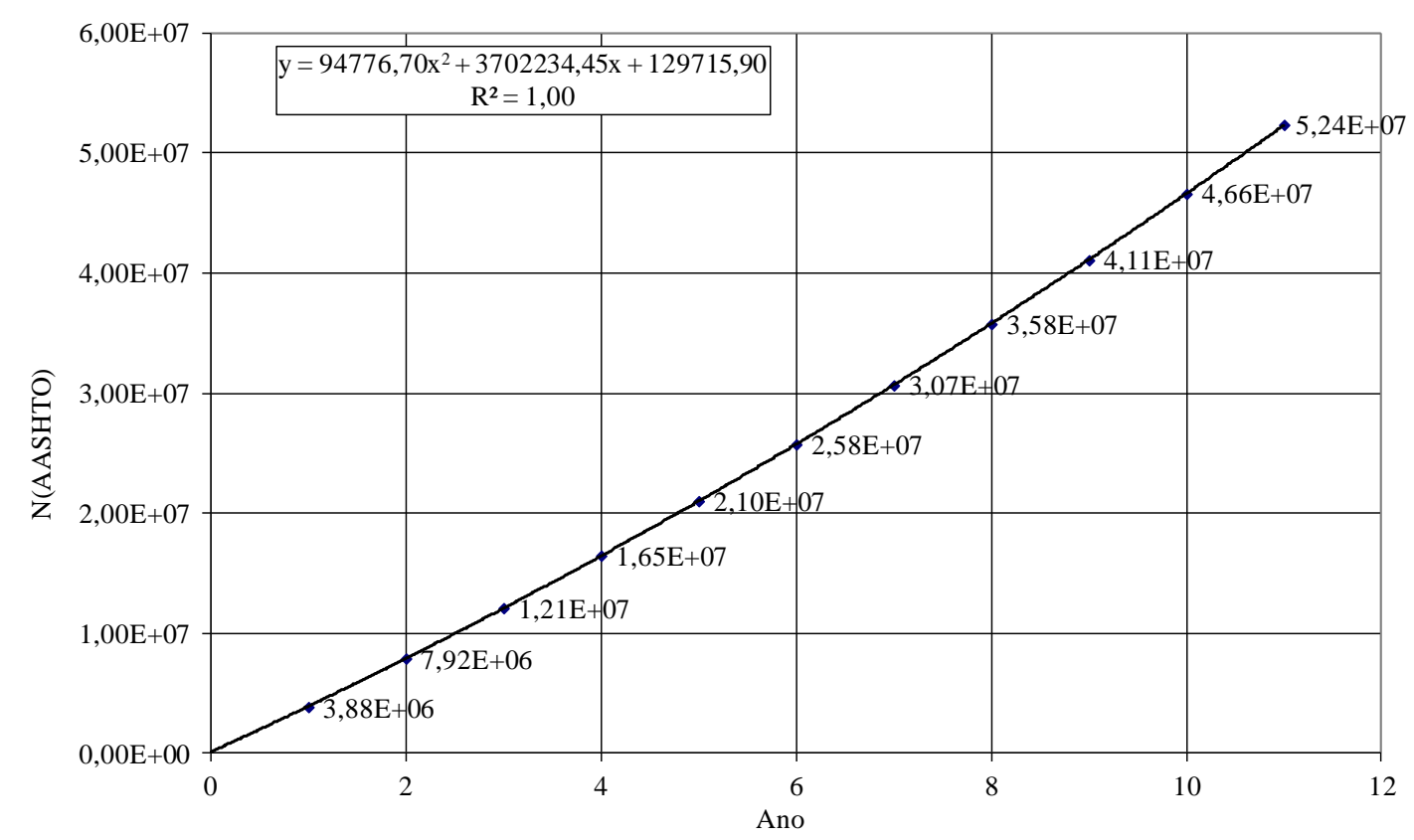

Figura 3: Determinação do número N acumulado (2012-2021) da BR-101/SE pelo método da AASHTO (1993) (Fonte: MENDONÇA, 2013) [12].

\section{METODOLOGIA}

As análises compreenderam a comparação entre as estruturas elásticas obtidas em campo, através de retroanálise de bacias deflectométricas medidas com $F W D$, e em laboratório, através de ensaios de carga repetida para obtenção de módulos de resiliência de misturas asfálticas e de materiais granulares.

Foram extraídos corpos de prova de misturas asfálticas em campo através de sonda rotativa. As amostras de solo foram retiradas do pavimento através de abertura de janelas no pavimento. Tanto as amostras de solo, quanto de misturas asfálticas (03 réplicas) foram extraídas do bordo direito da faixa de rolamento da direita, considerada a de maior solicitação de tráfego. Os ensaios de módulo de resiliência de misturas asfálticas foram realizados a partir de procedimento determinado pela norma DNIT 135/2010-ME [13] e os de solos pela norma DNIT 134/2010-ME [5].

O software utilizado para processar a retroanálise de bacias deflectométricas com $F W D$ foi o EverCalc 5.0. O EverCalc Pavement Backcalculation Program Version 5.20 é um software constituinte do pacote de softwares para análise mecanística de pavimentos, com domínio aberto (EVERSERIES), desenvolvido pelo Materials Laboratory do Washington State Department of Transportation. Este software é capaz de realizar retroanálises de até 5 camadas de pavimentos, utilizando dados de 10 sensores de $F W D$ e oito avaliações na mesma posição, tornando possível analisar a não linearidade elástica das camadas granulares [14]. Para este trabalho, foram realizadas quatro análises com cargas diferentes em uma mesma posição, sendo elas: $25 \mathrm{kN}, 42$ $\mathrm{kN}, 62 \mathrm{kN}$ e $82 \mathrm{kN}$. Assim, foi possível obter as bacias de deflexão e com o processo de retroanálise, os módulos de resiliência não lineares, das camadas sensíveis ao estado de tensões, e lineares para as demais.

Após os procedimentos de campo e laboratório, foram realizadas análises de tensão e deformação para a estrutura do pavimento definida na Tabela 1, mas com características elásticas obtidas por ensaios de laboratório e por retroanálises. Foi utilizado o software EVERSTRESS 5.0 para tanto (determinando tensões, deformações e deslocamentos de um sistema elástico de camadas finitas sob cargas superficiais circulares). O programa pode analisar a estrutura de pavimentos com até 5 camadas, 20 cargas e 50 pontos de avaliação [15]. Os dados de entrada são o número de camadas, suas características elásticas e os modelos elásticos adotados (Bulk Stress, Desviator Stress e Linear Modulus), além das configurações de 
carregamento e dos pontos de avaliação. Para as camadas asfálticas, foi usado o modelo linear. Já para as camadas de solo, usou-se os modelos que levaram a um maior $\mathrm{R}^{2}$ para os resultados de laboratório e modelos não-lineares obtidos na retroanálise.

Após as análises de tensão, deformação e deslocamentos, forma utilizados os modelos de previsão de desempenho empírico-mecanísticos do método de projeto da República SulAfricana para avaliar a durabilidade das camadas do pavimento. Os modelos de previsão de desempenho utilizados neste trabalho possibilitando avaliar o pavimento em termos de Número Acumulado de Repetições de Eixo Padrão de 8,2tf, para níveis de confiabilidade diferentes, através das seguintes respostas [16]:

- Misturas Asfálticas: Deformação Específica de Tração na base da camada asfáltica $\left(\varepsilon_{t}\right)$ causando dano por fadiga.

- Bases e Sub-bases Granulares: Deformações Permanentes derivadas tensões cisalhantes que acontecem no meio da camada granular. O cálculo é realizado a partir de uma Razão de Tensões calculada $(F)$.

- Bases e Sub-bases Cimentadas: Leva em consideração a Tensão Vertical de Compressão no topo da camada $\left(\sigma_{\mathrm{v}}\right)$ e a Deformação Específica de Tração na base da camada $\left(\varepsilon_{\mathrm{t}}\right)$ para avaliação de ruptura por esmagamento e por fadiga, respectivamente.

- Subleito: Deformação Vertical de Compressão no topo da camada $\left(\varepsilon_{\mathrm{v}}\right)$.

O programa de cálculo de tensões, deformações e deslocamentos pelo Método dos Elementos Finitos Tridimensional (EFin3D) foi desenvolvido, aproveitando rotinas específicas do software de código livre RIOPAVE e tendo como base o programa exemplo do curso de Introdução ao Método dos Elementos Finitos do Programa de Engenharia Civil do Instituto Alberto Luiz Coimbra de Pós-Graduação e Pesquisa de Engenharia (COPPE) da Universidade Federal do Rio de Janeiro [17], com o objetivo de adaptar a técnica do MEF à particularidade da análise de estruturas de pavimentos [18].

Antes de iniciar os cálculos do Método dos Elementos Finitos, foi definida a geometria dos elementos da malha, os parâmetros do carregamento, as condições de contorno e as propriedades dos materiais [19]. A malha usada foi definida pelo próprio programa e não teve refinamentos. Os dados de entrada do EFin3D são os mesmos usados para o EVERSTRESS 5.0. Para a análise em campo, foram usadas as estacas 655, 661, 663, 665 e 667, pois apresentaram resultados satisfatórios.

\section{RESULTADOS E DISCUSSÕES}

Os ensaios de Módulo de Resiliência foram realizados para três tipos de materiais: misturas asfálticas, BGTC e solos.

Para as misturas asfálticas, além do módulo de resiliência, foi obtida a Resistência a Tração por Compressão Diametral (RT), conforme a norma DNIT ME 136/2010 [19]. Os resultados encontrados estão presentes na Tabela 2.

Tabela 2: Resultados de MR e RT para misturas asfálticas.

\begin{tabular}{ccc}
\hline Características & Capa & Binder \\
\hline MR (MPa) & $4.273,49$ & $9.308,73$ \\
\hline RT (MPa) & 1,492 & 2,031 \\
\hline MR/RT & 2.864 & 4.583 \\
\hline
\end{tabular}

Os gráficos com os resultados dos ensaios de MR de solos são apresentados nas Figuras 4, 5 e 6, respectivamente para solo de subleito e sub-base, em função das tensões totais e das tensões desvio. Na Tabela 3 são apresentados os modelos obtidos no ensaio em função da tensão desvio ou do somatório de tensões, além da consideração do efeito da pressão atmosférica, requisito para a entrada de dados na análise não linear do EVERSTRESS 5.0. Devido à necessidade do próprio EVERSTRESS 5.0 para análise não linear nos cálculos de tensões e deformações, os modelos apresentados nas Figuras 4 e 5 foram ajustados em forma de potência, o que resultou em $\mathrm{R}^{2}$ relativamente baixo. Certamente outros modelos de ajustes poderiam fornecer $\mathrm{R}^{2}$ 
maiores. Contudo, como a magnitude de tensões verticais que alcançarão a sub-base e o subleito é inferior à $300 \mathrm{kPa}$, ambos os modelos são válidos até este valor.

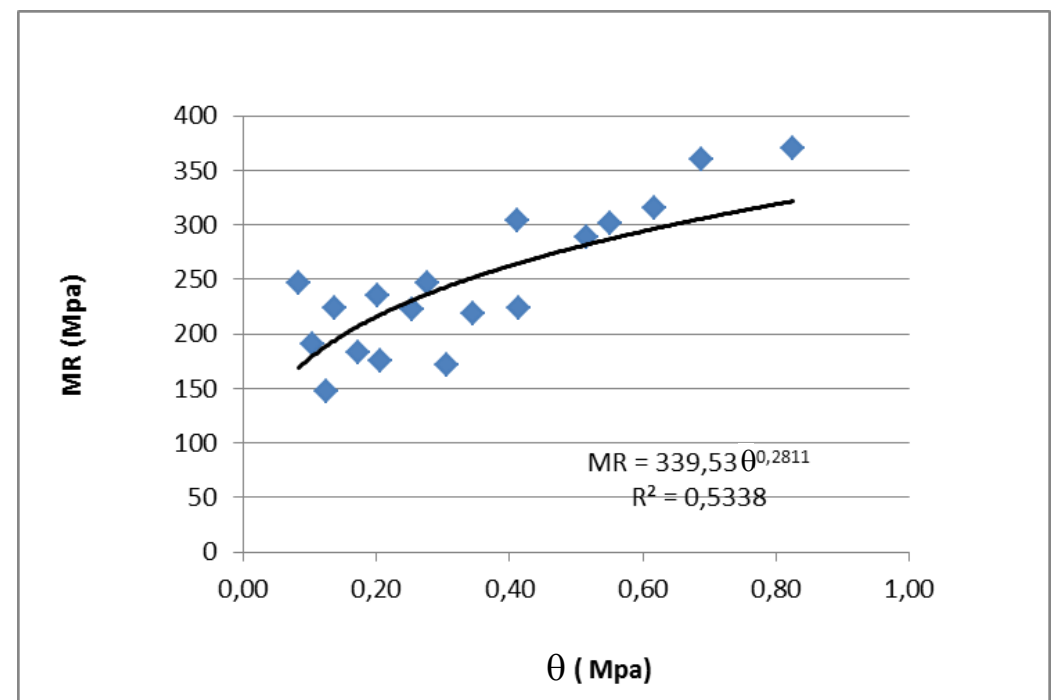

Figura 4: Módulo de Resiliência do Subleito do Trecho Monitorado A.

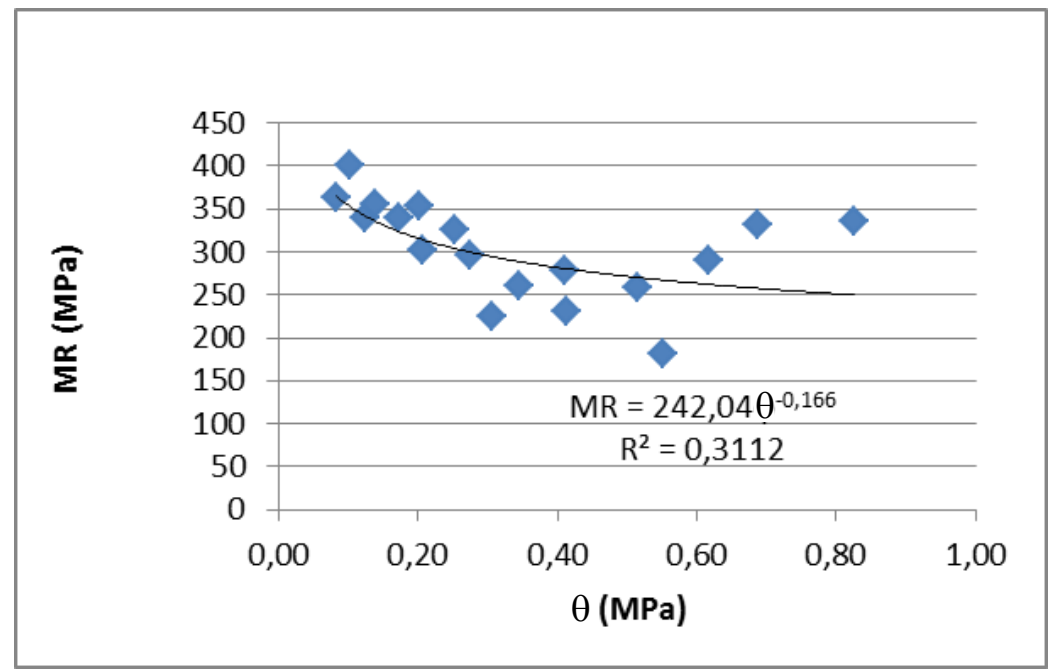

Figura 5: Módulo de Resiliência da Sub-base do Trecho Monitorado A.

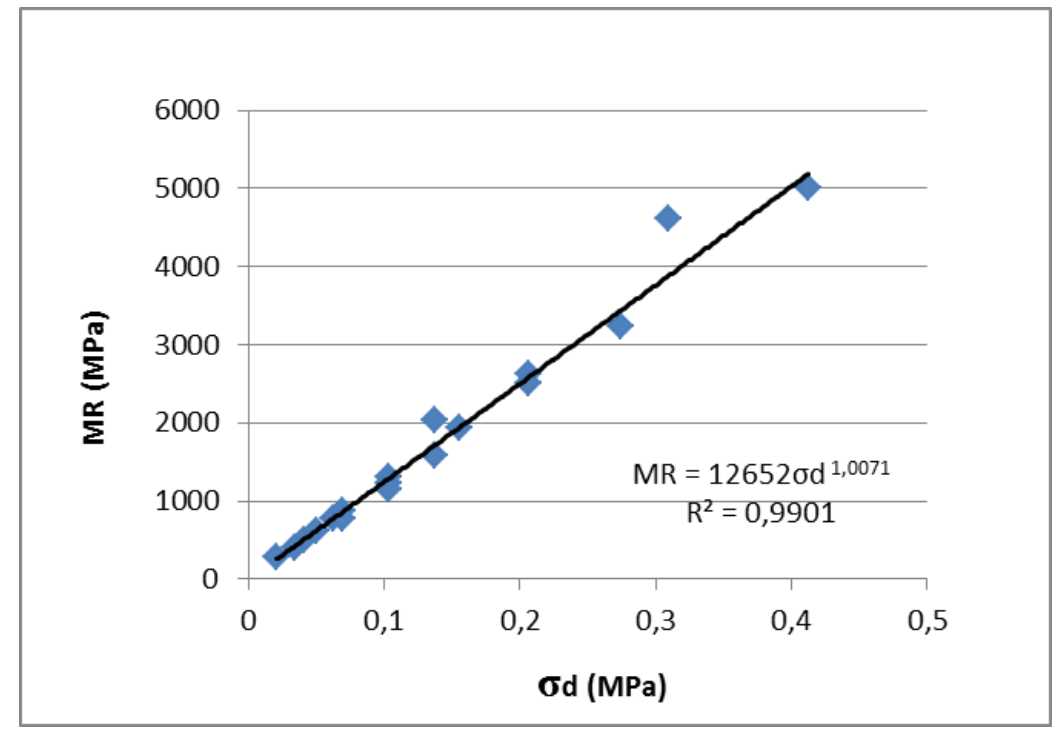

Figura 6: Módulo de Resiliência da Base do Trecho Monitorado A. 
Tabela 3: Resultados de MR para os solos analisados considerando requisitos do EVERSTRESS 5.0 (em função da pressão atmosférica).

\begin{tabular}{cccc}
\hline Estaca 664 & Modelo $(\mathbf{M P a})$ & $\mathbf{R}^{\mathbf{2}}$ & Tipo de Modelo \\
\hline Subleito & $M r=178,40(\theta / \text { Patm })^{-0,281}$ & 0,53 & Somatório de Tensões \\
\hline Sub-base & $M r=354,00(\theta / \text { Patm })^{-0,166}$ & 0,31 & Somatório de Tensões \\
\hline Base & $M r=1262,00\left(\sigma_{d} / \text { Patm }\right)^{1,007}$ & 0,99 & Tensão Desvio \\
\hline
\end{tabular}

Nos trabalhos de campo, o $F W D$ foi utilizado no trecho monitorado nas estacas 655,661 , 663,665 e 667, tendo a aplicação das seguintes cargas aproximadamente: $25.000 \mathrm{~N}, 42.000 \mathrm{~N}$, $62.000 \mathrm{~N}$ e $82.000 \mathrm{~N}$ em cada ponto. Os resultados das retroanálises estão na Tabela 4 para uma carga padronizada de 40.000 N. Nesta tabela são apresentados os Módulos de Resiliência (MRs) descritos através de modelos constitutivos e os módulos elásticos lineares equivalentes de cada camada do pavimento. Ainda, são apresentados os módulos elásticos para a configuração obtida em ensaios de laboratório. Nenhuma das configurações retroanalisadas foram semelhantes à obtida em laboratório.

Para efeito de comparação, todas as estruturas analisadas foram processadas pelo software EVERSTRESS 5.0. Desta forma, todos os módulos de resiliência descritos por equações constitutivas não lineares tiveram a padronização em valores lineares equivalentes.

Os resultados encontrados para a camada de revestimento asfáltico foram $4270 \mathrm{MPa} e m$ laboratório e entre 1000 a $1500 \mathrm{MPa}$ em campo. O fator que certamente causou as diferenças nos valores de MR foi a temperatura da mistura asfáltica durante o ensaio com $F W D$. A camada de revestimento, principalmente por ter pequena espessura $(5 \mathrm{~cm})$, tem módulo de resiliência bastante susceptível às variações de temperatura devido este material ter o comportamento condicionado pelo ligante asfáltico, o qual é aproximadamente viscoelástico [8]. Contudo, ambos os resultados diferem dos apresentados na literatura, pois registros de MR em misturas asfálticas com SBS foram aproximadamente 2500-3000 MPa [1 e 20].

Tabela 4: Módulos de Resiliência obtidos em laboratório e por retroanálise.

\begin{tabular}{ccccccc}
\hline & \multicolumn{7}{c}{ MR (MPa) } \\
\cline { 2 - 7 } Camadas & Lab SLH2 & Est 655 & Est 661 & Est 663 & Est 665 & Est 667 \\
\hline Capa & 4273 & 1002 & 1429 & 1198 & 1000 & 1190 \\
\hline Binder & 9309 & 10937 & 10096 & 10837 & 4357 & 11233 \\
\hline Base & 4032 & 5729 & 4228 & 8385 & 1519 & 8322 \\
\hline modelo & $M R=1262\left(\frac{\sigma_{d}}{P}\right)^{1,007}$ & $M R=5510\left(\frac{\sigma_{d}}{P}\right)^{-0,03}$ & $M R=2136\left(\frac{\sigma_{d}}{P}\right)^{-0,49}$ & - & - & - \\
\hline Sub-base & 293 & 1765 & 1810 & 547 & 1979 & 535 \\
\hline modelo & $M R=354\left(\frac{\theta}{P}\right)^{-0,166}$ & $M R=185\left(\frac{\sigma_{d}}{P}\right)^{-1,08}$ & $M R=436\left(\frac{\sigma_{d}}{P}\right)^{-0,69}$ & $M R=193\left(\frac{\sigma_{d}}{P}\right)^{-0,36}$ & $M R=668\left(\frac{\sigma_{d}}{P}\right)^{-0,58}$ & $M R=224\left(\frac{\sigma_{d}}{P}\right)^{-0,30}$ \\
\hline Subleito & 136 & 305 & 403 & 578 & 477 & 578 \\
\hline modelo & $M R=178\left(\frac{\theta}{P}\right)^{0,281}$ & - & - & - & - & - \\
\hline \multicolumn{7}{c}{$P=$ pressão atmosférica em MPa $\rightarrow$ requisito para análise não linear do MR no EVERSTRESS 5.0. }
\end{tabular}

A camada de binder apresentou resultados semelhantes entre os resultados de ensaios de laboratório e os retroanalisados, ficando em torno de $9300 \mathrm{MPa}$ e $10500 \mathrm{MPa}$, respectivamente. A exceção foi o MR retroanalisado da estaca 665, cuja diferença foi de quase $60 \%$ para os demais.

Para a base de BGTC os resultados retroanalisados tiveram variações consideráveis entre as estacas (entre $1260 \mathrm{MPa}$ a $8380 \mathrm{MPa}$ ), porém a média dos valores (4580 MPa) foi bem próxima ao MR equivalente linear (4030 MPa) da configuração de laboratório (Tabela 5). As trincas longitudinais e transversais ao longo do trecho monitorado podem ter reduzido o MR em algumas estacas, tal como ocorreu no revestimento. Esta já apresentava dano por fadiga em menos de um ano de abertura ao tráfego. 
Tabela 5: Dados obtidos de tensões e deslocamentos pelo EVERSTRESS 5.0.

\begin{tabular}{cccc}
\hline Configuração & \multicolumn{2}{c}{$\boldsymbol{\varepsilon}_{\mathbf{t}}\left(\mathbf{1 0}^{-\mathbf{6}} \mathbf{~} \mathbf{c m} / \mathbf{c m}\right)$} & $\sigma_{\mathbf{v}}(\mathbf{k P a})$ \\
\cline { 2 - 4 } & Binder & Base & Base \\
\hline Lab SLH2 & 26 & 88 & 324 \\
\hline Estaca 655 & 17 & 41 & 414 \\
\hline Estaca 661 & 26 & 41 & 392 \\
\hline Estaca 663 & 10 & 46 & 427 \\
\hline Estaca 665 & 73 & 39 & 385 \\
\hline Estaca 667 & 10 & 46 & 424 \\
\hline
\end{tabular}

Na Figura 7 (a e b), são apresentados os gráficos de deslocamentos verticais (perfil de deflexões) em um comparativo entre a configuração resultante de ensaios de laboratório e as retroanalisadas de bacias deflectométricas. Observa-se nos perfis de deflexão que os deslocamentos totais ficaram entre $83 \times 10^{-3} \mathrm{~mm}$ e $119 \times 10^{-3} \mathrm{~mm}$ para as bacias deflectométricas medidas. Enquanto isso, o deslocamento total estimado para a estrutura com MRs obtidos em laboratório foi pelo menos o dobro do observado em campo $\left(236 \times 10^{-3} \mathrm{~mm}\right)$. As configurações de campo apresentaram-se mais rígidas que a obtida por ensaios de MR em laboratório, mesmo com a diferença do MR da capa, conforme já comentado anteriormente. Diferenças importantes foram observadas na comparação de resultados de MR dos ensaios triaxiais dinâmicos de solos e os valores retroanalisados para a camada de sub-base e para o subleito. Especialmente para a sub-base, a grande diferença foi na sensibilidade ao estado de tensão. Enquanto em laboratório observou-se variação mais efetiva com a variação de tensões totais, nas retroanálises a tensão desvio foi mais importante.

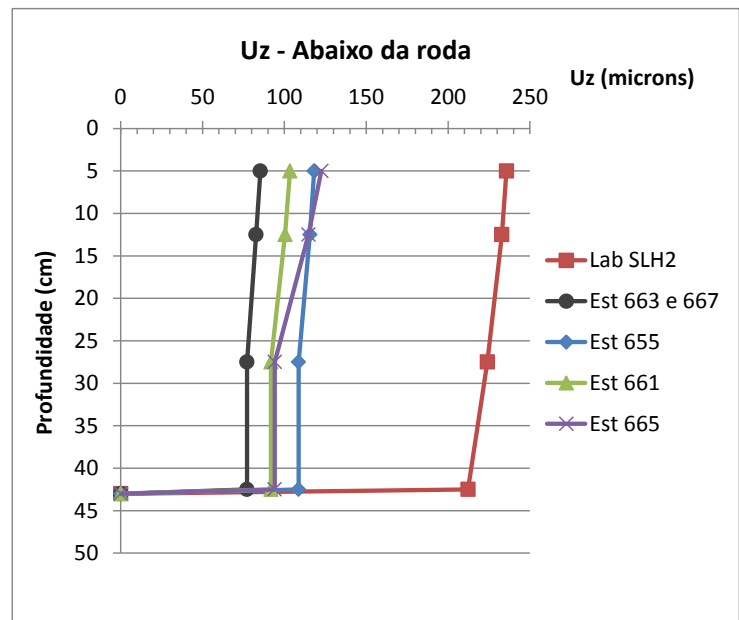

(a)

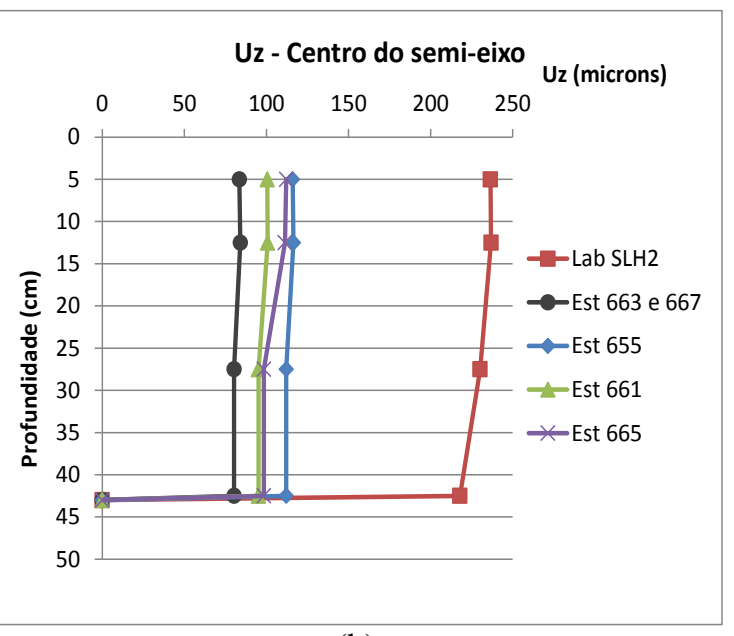

(b)

Figura 7: Deflexões (Uz) abaixo da roda (a) e no centro do semieixo (b), obtidas pelo EVERSTRESS 5.0.

Na Tabela 5, observam-se os resultados de deformação específica de tração nas bases das camadas de Binder e da Base de BGTC, e tensão vertical no topo da camada de Base de BGTC. Exceto para a Estaca 665, as deformações específicas de tração no Binder obtidas no EVERCALC 5.0 foram baixas, não proporcionando dano por fadiga a esta camada. Contudo, utilizando-se modelos do método de projeto empírico-mecanístico da República Sul-Africana, na Estaca 665 o início do trincamento na base da camada asfáltica aconteceria no $2^{\circ}$ ano de serviço $\left(\mathrm{N}=6,33 \times 10^{6}\right)$. O trincamento atingiria cerca de $20 \%$ do topo da camada ao final da vida de projeto (10 anos).

Observou-se com a aplicação de modelos do método de projeto empírico-mecanístico da República Sul-Africana, que a camada que tem comportamento crítico para a estrutura do pavimento é a Base de BGTC. O esmagamento causado pelo efeito da tensão no topo desta camada e, principalmente, o processo de fadiga devido à deformação específica de tração na base desta camada, resultaram em uma vida de serviço estimada menor que 2 anos. De fato, em avaliações de campo realizadas ao $2^{\circ}$ ano de serviço, já foram observados trincamentos surgindo 
no topo do revestimento asfáltico. Estes trincamentos foram ocasionados por reflexão de trincas da Base de BGTC. Na Tabela 6, observam-se as previsões de danos por fadiga na Base de BGTC. Mesmo sabendo do desempenho insatisfatório deste trecho monitorado, observou-se que a configuração elástica das camadas obtida por ensaios de laboratório acabou subestimando a vida de serviço real do pavimento, indicando $20 \%$ de trincamento da Base de BGTC em apenas 1 ano, enquanto, para as configurações obtidas por retroanálises, as estimativas indicaram 2 anos.

Tabela 6: Resultados de estimativa de dano por fadiga na camada de Base de BGTC com modelos do método de projeto mecanístico-empírico da República Sul-Africana.

\begin{tabular}{|c|c|c|c|c|c|c|c|c|c|}
\hline \multicolumn{2}{|c|}{ Integridade } & \multicolumn{2}{|c|}{$50 \%$} & \multicolumn{2}{|c|}{$80 \%$} & \multicolumn{2}{|c|}{$90 \%$} & \multicolumn{2}{|c|}{$95 \%$} \\
\hline Configuração & $\begin{array}{c}\text { Et } \\
\left(10^{-6} \mathrm{~cm} / \mathrm{cm}\right)\end{array}$ & Nf & Ano & $\mathbf{N f}$ & Ano & Nf & Ano & $\mathbf{N f}$ & Ano \\
\hline Lab SLH2 & 88 & $3,65 \mathrm{E}+06$ & 1 & $2,36 \mathrm{E}+06$ & 1 & $2,20 \mathrm{E}+06$ & 1 & $1,67 \mathrm{E}+06$ & 1 \\
\hline Estaca 655 & 41 & $7,88 \mathrm{E}+06$ & 2 & $5,09 \mathrm{E}+06$ & 2 & $4,76 \mathrm{E}+06$ & 2 & $3,61 \mathrm{E}+06$ & 1 \\
\hline Estaca 661 & 41 & $7,88 \mathrm{E}+06$ & 2 & $5,09 \mathrm{E}+06$ & 2 & $4,75 \mathrm{E}+06$ & 2 & $3,60 \mathrm{E}+06$ & 1 \\
\hline Estaca 663 & 46 & $7,31 \mathrm{E}+06$ & 2 & $4,72 \mathrm{E}+06$ & 2 & $4,41 \mathrm{E}+06$ & 2 & $3,34 \mathrm{E}+06$ & 1 \\
\hline Estaca 665 & 39 & $8,21 \mathrm{E}+06$ & 3 & $5,31 \mathrm{E}+06$ & 2 & $4,95 \mathrm{E}+06$ & 2 & $3,76 \mathrm{E}+06$ & 1 \\
\hline Estaca 667 & 46 & $7,28 \mathrm{E}+06$ & 2 & $4,71 \mathrm{E}+06$ & 2 & $4,39 \mathrm{E}+06$ & 2 & $3,33 \mathrm{E}+06$ & 1 \\
\hline
\end{tabular}

Para a comparação entre os métodos de cálculo de tensões e deformações (camadas finitas e elementos finitos) utilizou-se os programas computacionais, EVERSTRESS 5.0 e o EFin3D, para os respectivos métodos. A análise foi realizada na posição do centro do semieixo dos veículos.

Quando se tratou de tensões verticais, o EFin3D apresentou resultados inferiores quando comparados ao EVERSTRESS 5.0 em quase todas as camadas. Apenas a camada de subleito apresentou resultados superiores, pois, o programa de Camadas Finitas supõe que o carregamento seja dissipado ao longo da estrutura do pavimento, portanto, as cargas não atingem o subleito, não causando tensões no mesmo.

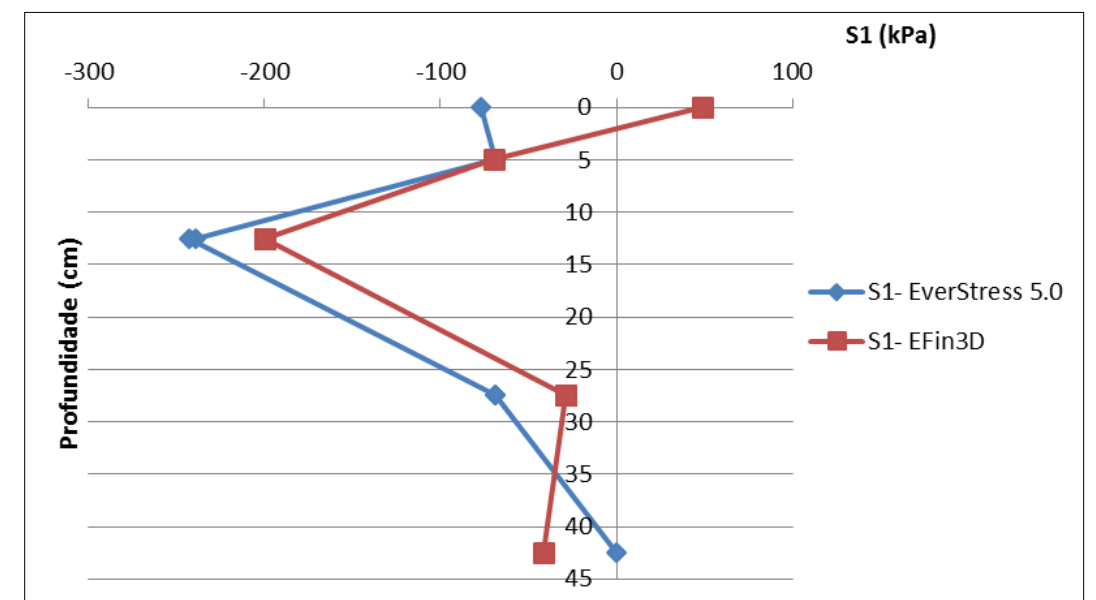

Figura 08: Tensões verticais (S1) no centro do semieixo obtidas pelo EVERSTRESS e pelo EFin3D.

\section{CONCLUSÃO}

Neste trabalho foram avaliadas as diferenças dos módulos elásticos medidos em laboratório e retroanalisados em campo.

O módulo de resiliência da camada de binder obtido em laboratório foi semelhante ao obtido por retroanálises de bacias deflectométricas medidas com $F W D$. Quanto à camada de revestimento, os valores de MR obtidos em ensaios laboratoriais foram bem superiores aos 
retroanalisados, possivelmente devido às temperaturas mais elevadas da mistura asfáltica em campo.

Observaram-se grandes diferenças no comportamento dos modelos constitutivos e nos valores lineares dos módulos de resiliência obtidos em ensaios triaxiais dinâmicos da base de BGTC, e dos solos de sub-base e subleito do trecho monitorado, com relação aos obtidos por retroanálises de bacias deflectométricas medidas a partir de quatro carregamentos diferentes. $\mathrm{O}$ ensaio triaxial dinâmico pode induzir condições de contorno distintas das condições observadas em campo.

$\mathrm{Na}$ análise feita neste trabalho, a configuração estrutural obtida por ensaios de laboratório acabou subestimando o desempenho previsto para o pavimento a partir dos resultados de retroanálises. Isto pode ser um indicador de que as condições com que os pavimentos são executados em campo podem ser diferentes das reproduzidas em laboratório.

Para este trabalho foi utilizada também a malha de elementos finitos definida pelo próprio programa EFin3D. O cálculo de tensões, deformações e deslocamentos por esse método poderia ser diferente com o refinamento da malha geométrica, o que poderia gerar resultados mais precisos.

Para o trecho estudado, o método da teoria do sistema de camadas finitas (EVERSTRESS 5.0) forneceu resultados mais conservadores (mais altos), quando comparado ao método dos elementos finitos (EFin3D). Isto pode ser um bom indicador, já que a maior parte dos métodos de projeto de pavimentos faz uso da TSCE.

\section{AGRADECIMENTOS}

Ao DNIT-SE pela contribuição direta na realização desta pesquisa, inclusive pelo apoio e realização dos levantamentos de campo.

\section{REFERÊNCIAS BIBLIOGRÁFICAS}

1. Bernucci LB, et al. Pavimentação Asfáltica- Formação Básica para Engenheiros. Rio de Janeiro: [s.n.]. 2007.

2. Balbo JT. Pavimentação asfáltica: materiais, projeto e restauração. Oficina de Textos. São Paulo: [s.n.]. 2007.

3. DNIT. Manual de Pavimentação. 3ª ed. Rio de Janeiro. 2006.

4. Medina J, Motta LG. Mecânica dos Pavimentos. [S.1.]: ABMS. 2005.

5. DNIT. ME 134/2010. Pavimentação - Solos - Determinação do módulo de resiliência -Método de Ensaio. Rio de Janeiro - RJ. 2010.

6. Hicks RG. Factors Influencing the Resilient Properties of Granular Materials, PhD Thesis, University of California, Berkley. 1970.

7. Nóbrega ES. Comparação entre métodos de retroanálise em pavimentos asfálticos. Dissertação de Mestrado. COPPE/UFRJ. Rio de Janeiro - RJ. 2003. 365 p.

8. Huang YH. Pavement Analysis and Design: Prentice-Hall, 2nd Edition. New Jersey. 2003.

9. Soriano H. Método de elementos finitos em análise de estruturas. São Paulo: Edusp. 2003.

10. Alves Filho A. Elementos Finitos: A Base da Tecnologia CAE. Análise Dinâmica. São Paulo: Érica, 2005. 304 p.

11. AASTHO. AASHTO Guide for Design of Pavement Structures. American Association of States Highway and Transportation Officials. Washington, DCC/USA. 1993.

12. Mendonça AT. Plano de Qualificação de Mestrado: Avaliação de trechos monitorados na rodovia BR101/SE. Dissertação (Mestrado) — Universidade Federal de Sergipe, São Cristóvão. 2013.

13. DNIT. ME 135/2010. Pavimentação asfáltica - Misturas asfálticas - Determinação do módulo de resiliência - Método de Ensaio. Rio de Janeiro - RJ, 2010.

14. Albuquerque FS. Sistema de gerência de pavimentos para Departamentos de Estradas do Noroeste brasileiro. Tese (Doutorado) — Universidade Federal do Rio Grande do Sul. 2007.

15. WSDOT. Washington State Department of Transportation, Manual do EVERSERIES: Pavement Analysis Computer Software and Case Studies. 2005.

16. SANRA. South African Pavement Engineering Manual. 2003. South African National Roads Agency. 
17. Ribeiro. Programa exemplo do curso de Introdução ao Método dos Elementos Finitos do Programa de Engenharia Civil da COPPE. 2003.

18. Franco FACP. Manual do Usuário: Programa EFin3D. 1 ${ }^{\mathrm{a}}$. ed. [S.1.]. 2007.

19. DNIT. ME 136/2010 - Pavimentação asfáltica - Misturas asfálticas - Determinação da resistência à tração por compressão diametral - Método de ensaio. Rio de Janeiro: IPR. 2010.

20. Gusmao M. Restauração Rodoviária Usando Asfalto Modificado por Polímero. Dissertação de Mestrado - Universidade Federal de Ouro Preto. Escola de Minas. Departamento de Engenharia Civil. Programa de Pós- Graduação em Engenharia Civil. Minas Gerais. 2009. 